\title{
Assessment of mental health status and its effective components among professional urban bus drivers in Qom Province, Iran, in 2014
}

\author{
Koohpaei AR, $\mathrm{PhD}^{1}$, Khandan M, MSc ${ }^{2 *}$ \\ 1- Associate prof., Dept of. Occupational Health Engineering, Faculty of Health, work health research center, Qom \\ University of Medical Sciences, Qom, Iran. 2- Instructor, Dept of. Ergonomics, Faculty of Health, Qom University of \\ Medical Sciences, Qom, Iran.
}

\begin{abstract}
Received: January 2016, Accepted: April 2016

Background: The physical and psychological health of bus drivers is a critical factor in public driving performance. Any impairment can have dire consequences for passengers and the company. Thus, research on the mental health status of public bus drivers is a critical issue in reducing road accidents, decreasing passengers' injuries, and ensuring the safety of the operation.

Materials and Methods: A descriptive cross-sectional study was carried out in 2014 and the 28-item General Health Questionnaire (GHQ-28) was used for the psychological health measurement of 214 consenting bus drivers in Qom Province of Iran. In addition, a demographic questionnaire was applied. Data were analyzed in SPSS software.

Results: All drivers (except one) were men with a mean age of $34.25 \pm 7.49$ years. The majority of the participants $(207 ; 96.7 \%)$ were married. Based on the average scores obtained from GHQ-28 $(21.45 \pm 12.88)$, general psychological morbidity was $35.98 \%$. Moreover, the components of somatic symptoms, sleep disorders and anxiety, social dysfunction, and depression were experienced by $33.64 \%, 40.65 \%, 50.93 \%$, and $13.08 \%$ of bus drivers, respectively. The questionnaire data indicated that age $(\mathrm{P}<0.05)$ and marital status (differences were not significant) played an important role in influencing mental health among the bus drivers.

Conclusions: It can be concluded that drivers' physical and mental health are areas of concern that need to be addressed alongside the development of specific methodologies for permanent monitoring of these factors at specific times as permanent training and evaluation are necessary. The data obtained in the present study showed that prevention strategies such as routine evaluations, recording, and analysis of mental health status among drivers must be effective and applicable.
\end{abstract}

Keywords: Mental Health, Depression, Safety, Iran.

\section{Introduction}

According to the World Health Organization (WHO), the rate of mortality due to traffic accidents in low and middle income countries was higher than in developed countries. In addition, over $90 \%$ of deaths occur in developing countries $(1,2)$, while half of the total number of vehicles in the world are used in these countries (3). The average cost per accident in the United States is 533 million dollars and 11.7 million dollars in the case of a death (4). In such circumstances, it seems the use of public transport like buses is one of the ways to overcome this challenge. For example, in Beijing, China, 27, 963 buses in the 882 line passes between different start and destination points, travel 1.4 billion kilometers, and carry 5 million passengers annually (5). Given that a large share of transportation within cities are carried out by urban buses, drivers' skills, bus type, road conditions, the appropriate number of buses, the behavior of other drivers, passengers' behavior, the streets, traffic culture, fare payment systems, organizational

\footnotetext{
* Corresponding author: Mohammad Khandan, Dept of. Ergonomics, Faculty of Health, Qom University of Medical Sciences, Qom, Iran. Email: mkhandan@ muq.ac.ir
} 
issues, and social and economic factors can play an important role in urban safety (5).

The role of drivers is crucial and scientists have considered reviewing and modifying human factors as well as amending job requirements in order to reduce road accidents (6). It is estimated that $90-95 \%$ of accidents are due to human factors (7). Undoubtedly, if the drivers are in good physical and mental conditions, comfortable urban journeys will be largely provided (5). In a comprehensive review of 50 years on the health of drivers, Tse et al. concluded that heavy traffic, passengers' expectations, and compressed timelines placed permanent pressure on drivers and threatened their health (8).

In another study, $50 \%$ of drivers evaluated their jobs as heavy and stressful (9). The physical and mental health of bus drivers is an important factor in driving (10). High levels of physical and psychological injuries and disorders of professional drivers have been depicted in literature reviews. It has been reported that $97.9 \%$ of drivers had musculoskeletal disorders (MSDs) (11), about $60 \%$ of drivers experienced sleep problems (1), $13.6 \%$ suffered from depression (12), $43.7 \%$ of drivers reported sleepiness while driving (13), and more than half of drivers had blood pressure problems (14). Furthermore, weight gain and obesity were observed among drivers (15), $23.6 \%$ of drivers showed symptoms of anxiety (16), 55\% of drivers were fatigued during their performance of activities (17), $61 \%$ had poor sleep quality (14), $76 \%$ of drivers had high levels of occupational stress (18) that were related to cancer, cardiovascular diseases, stroke, crashes, and low mental health (6), and $75 \%$ of drivers were drug abusers (16). A study analyzed 32 researches conducted from 1995 to 2012 among 151,644 drivers, and the results demonstrated that $19 \%$ of drivers had sleep disorders, $33 \%$ had diabetes, $23 \%$ had high or low blood pressure, and $45 \%$ were obese and had sleep disorders. Obesity was associated with an increased risk of accidents (19). Studies depicted that health level and quality of drivers' working life were lower than the general population $(20,21)$.

The major problems experienced by drivers are psychosocial issues such as stress, shift work, and intense work schedule (1). Direct interaction with various strata, recklessness by other drivers and pedestrians, slow traffic in narrow streets, old buses, high numbers of passengers and etcetera, all would be assumed as causes of a collision between the passenger and driver that will intensify environmental and organizational pressures (22). Increased workload threatens drivers' health, and leads to risky behaviors by the drivers and decreased attention and concentration (23).

Based on the abovementioned facts, it seems that improving drivers' health status has serious impact on the health of other individuals in the society. The first step toward the planning and modification of drivers' health status is accurate data gathering. Although some researchers have studied this important issue, there is a lack of comprehensive information on drivers' physical and mental health in Iran (7, 24-27). Goldberg's 28-item General Health Questionnaire (GHQ-28) has been applied as a useful tool to assess drivers' mental disorders (28). In order to plan for the promotion of the health of drivers, as one of the important subsets of urban health and safety, various studies are required to determine the health status of drivers in Iran. On this basis and as a small step, this study aimed to assess the mental health of urban bus drivers and factors affecting it in the bus driving company in Qom (one of the central provinces of Iran).

\section{Material and Methods}

It cross-sectional and descriptive-analytical study was carried out among 214 bus drivers (regardless of the 225 return rate) who were randomly selected from among bus driving company employees in Qom Province in 2014. According to equation 1 and standard deviation of $14(\mathrm{~S}=\mathrm{R} / 6)$ and based on the GHQ-28 score ranges $(\mathrm{R}=84)$ and alpha value 
of 0.05 , sample size was calculated as 188 . With regards to the $20 \%$ return rate, sample size was determined at 225 .

$n=\frac{Z_{1-\alpha / 2}{ }^{2} S^{2}}{d^{2}}=188$

(Equation 1)

The data collection tools consisted of a demographic questionnaire including items such as gender, marital status, and age, and the GHQ-28 containing the four subscales of physical symptoms, anxiety and insomnia, social dysfunction, and depression. The GHQ28 is scored based on a 4-point Likert scale ranging from 0 to 3 ; lower scores indicate a higher level of public health. The total score obtained by each respondent ranges from 0 to 84. Scores lower than or equal to 23 indicate that the respondent is healthy and scores of 24 or higher are illustrate suspected abnormalities (29). The cut-off point for each subscale is 6 . This means that in each subscale, scores of less than or equaled to 6 indicate that the individual is healthy and scores above 6 indicate unhealthy individuals (30). The total score of each subscale is within the range of 0 to 21 . The validity and reliability of GHQ-28 have been assessed in numerous studies. Taghavi studied the reliability and validity of the questionnaire and approved it for use in the Iranian society (31).

Selection of subjects was based on the bus drivers' registration; drivers' codes were randomly selected. Then, the names of drivers were identified, and a research team was located at bus drivers' fuel station as focus center. During the time period of fuelling, the questionnaires were distributed after the necessary explanations were given and the appropriate time was selected by a member of the research team. Then, questionnaires were completed by drivers. It should be noted that all questions of drivers were answers. All drivers were able to leave the study without any problems. Moreover, extra time has been considered to complete the questionnaires by drivers during the research process. The gathered data were analyzed using descriptive statistics, t-test, and the Pearson correlation in SPSS software (version 20, SPSS Inc., Chicago, IL, USA).

\section{Results}

There was only 1 woman among the 214 drivers who participated in this study and others were men (99.5\%). Furthermore, 207 (96.7\%) participants were married and only 7 were single. Drivers had an average age of $34.25 \pm 7.49$ years; the range of ages was 22 to 55 years.

All 214 delivered questionnaires were acceptable and computed into the main analysis. The results showed that the mean and standard deviation of public health was 21.45 \pm 12.88. Table 1 illustrates descriptive information on public health and its 4 components. Social dysfunction and depression symptoms by an average score of 6.82 to 2.69 had the best and the worst conditions, respectively.

Table 1: Descriptive data on general health and its scales $(n=214)$

\begin{tabular}{lccccc}
\hline Factor & $\begin{array}{c}\text { General } \\
\text { health }\end{array}$ & Depression & $\begin{array}{c}\text { Social } \\
\text { dysfunction }\end{array}$ & Sleeplessness & $\begin{array}{c}\text { Somatic } \\
\text { symptoms }\end{array}$ \\
\hline Mean & 21.45 & 5.71 & 6.22 & 6.82 & 2.69 \\
SD & 12.88 & 3.78 & 4.26 & 3.25 & 3.77 \\
Maximum & 79 & 19 & 21 & 21 & 21 \\
Minimum & 1 & 0 & 0 & 0 & 0 \\
\hline
\end{tabular}

In addition, with regard to the cut-off points (scores of 6 and 23, respectively, for the four components of general health and the total score), it was determined that $50.93 \%$ ( $\mathrm{n}=$
109) of the studied drivers had an unfavorable state in social functioning. On the other hand, only $13.8 \%$ of the participants had an undesirable status with regards to symptoms of 
depression. In addition, total general health had a score higher than 23 among 77 respondents. Information on this analysis is shown in table 2.

Table 2: Frequency (percentage) of unhealthy participants $(n=214)$

\begin{tabular}{lc}
\hline Factors & Unhealthy workers \\
\hline Somatic symptoms & $72(33.64)$ \\
Sleeplessness & $87(40.65)$ \\
Social dysfunction & $109(50.93)$ \\
Depression & $28(13.08)$ \\
General health & $77(35.98)$ \\
\hline
\end{tabular}

Furthermore, variables (five cases) were analyzed between the two groups in terms of marital status using t-test. However, in all cases, single people were more unacceptable than married individuals (with respect to quantities), but none was statistically significant $(\mathrm{P}>0.050)$. Differences in social dysfunction were considerable $(\mathrm{P}=0.093)$. Significant levels and the average scores of public health and its subscales based on marital status can be seen in table 3 .

Table 3: Comparison of the scores of general health and its subscales between married and single drivers

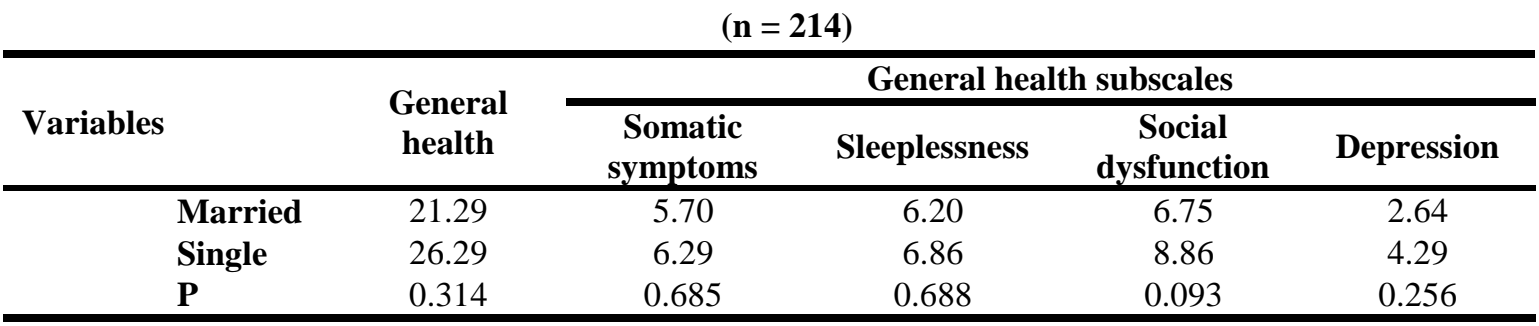

The relationship between age and general health scores and their subsidiaries were analyzed using the Pearson correlation coefficient. It was found that social dysfunction had a negative relationship with age $($ coefficient $=-0.156)(\mathrm{P}<0.050)$; this means the older the drivers, the better the social performance. Finally, the relationship between the general health subscales and the total score was satisfactory and varied between 0.812 and $0.902(\mathrm{P}<0.050)$ as presented in table 4.

Table 4: Pearson correlation coefficient and P-value for the relationship between general health and its subscales and age $(n=214)$

\begin{tabular}{|c|c|c|c|c|c|c|c|}
\hline & & $\begin{array}{c}\text { Somatic } \\
\text { symptoms }\end{array}$ & Sleeplessness & $\begin{array}{c}\text { Social } \\
\text { dysfunction }\end{array}$ & $\begin{array}{c}\text { Depres } \\
\text { sion }\end{array}$ & $\begin{array}{c}\text { General } \\
\text { health }\end{array}$ & Age \\
\hline Somatic symptoms & $\begin{array}{c}\text { Correlation } \\
\mathbf{P}\end{array}$ & $\begin{array}{c}1 \\
0.001\end{array}$ & & & & & \\
\hline Sleeplessness & $\begin{array}{c}\text { Correlation } \\
\mathbf{P}\end{array}$ & $\begin{array}{l}0.706 \\
0.001\end{array}$ & $\begin{array}{c}1 \\
0.001\end{array}$ & & & & \\
\hline Social dysfunction & $\begin{array}{c}\text { Correlation } \\
\mathbf{P}\end{array}$ & $\begin{array}{l}0.635 \\
0.001\end{array}$ & $\begin{array}{l}0.613 \\
0.001\end{array}$ & $\begin{array}{c}1 \\
0.001\end{array}$ & & & \\
\hline Depression & $\begin{array}{c}\text { Correlation } \\
\mathbf{P}\end{array}$ & $\begin{array}{l}0.566 \\
0.001\end{array}$ & $\begin{array}{l}0.715 \\
0.001\end{array}$ & $\begin{array}{l}0.584 \\
0.001\end{array}$ & $\begin{array}{c}1 \\
0.001\end{array}$ & & \\
\hline General health & $\begin{array}{c}\text { Correlation } \\
\mathbf{P}\end{array}$ & $\begin{array}{l}0.853 \\
0.001\end{array}$ & $\begin{array}{l}0.902 \\
0.001\end{array}$ & $\begin{array}{l}0.812 \\
0.001\end{array}$ & $\begin{array}{l}0.843 \\
0.001\end{array}$ & $\begin{array}{c}1 \\
0.001\end{array}$ & \\
\hline Age & $\begin{array}{c}\text { Correlation } \\
\mathbf{P}\end{array}$ & $\begin{array}{c}-0.081 \\
0.238\end{array}$ & $\begin{array}{c}-0.046 \\
0.504\end{array}$ & $\begin{array}{c}-0.156 \\
0.022\end{array}$ & $\begin{array}{c}-0.105 \\
0.127\end{array}$ & $\begin{array}{c}-0.109 \\
0.112\end{array}$ & $\begin{array}{c}1 \\
0.001\end{array}$ \\
\hline
\end{tabular}




\section{Discussion}

Urban bus drivers' physical and mental health is an important factor which affects their occupational performance. Any physical or mental disorder can lead to devastating consequences for drivers, passengers, and travel organizations (32). Mental disorders cause damage to attention, consciousness, performance, memory, and psychomotor ability. It should be noted that all of these critical factors were for professional driving (1). Our analysis based on the cut-off point showed that the mental health status of the studied drivers in general were not in high risk conditions, but there were a number of drivers that were impairment-suspected. This situation indicated that professional urban bus driving can lead to physical and mental damages. The general health components of somatic symptoms, sleeplessness and anxiety, social dysfunction, and depression were reported to be $33.64 \%, 40.65 \%, 50.93 \%$, and $13.08 \%$ in the studied drivers, respectively. In addition, a correlation was observed between age and general health $(\mathrm{P}<0.05)$. It should be noted that for the sake of comparison with other studies, the average age of drivers was important because older drivers were on their particular health conditions. The mean age of drivers in this study was similar to that of other studies on drivers around the world (13, 15, 28, 33-34). Components with good correlation with general health scores also showed the high reliability of the measurement tools for the assessment of mental disorders ( $\mathrm{P}$ $<0.05)$. Studies have indicated that young drivers had more mental health problems (1) and high-risk behaviors (35) that lead to accidents and injuries $(36,37)$, but drivers older than 35 years had more health problems, and this affected their driving performances (34). Significant differences between married and single drivers were not similar to the findings of Jahangiri et al. (24) and Francis (1). However, general health components were more satisfactory in all married drivers. The large difference between the number of single and married drivers in this study (7 to 207) can be due to the lack of statistically significant differences. Based on the data obtained from questionnaires, 72 professional drivers had physical symptoms. Musculoskeletal pain and digestive problems were common among the drivers. The same trend was observed in the scientific literature. It is clear that physical health status has a significant impact on driving tasks (6). Based on scientific researches, occupations were responsible for $37 \%$ of all backaches (38). Individuals with chronic diseases were 5.3 times more likely to be involved in accidents and individuals with cardiovascular diseases were 2 times more likely to have an accident (6).

A study in India showed that musculoskeletal problems were correlated with age, and duration and distance of driving per day (39). In other researches on Iranian drivers, it was revealed that musculoskeletal pain was a common problem (24) and greatly increased the absence of drivers (6). In addition, 78.7\%, $63.8 \%, 59.6 \%$, and $53.2 \%$ of Malaysian drivers had experienced pain in the waist, thigh, leg, and neck areas, respectively (11). Moreover, the results of a study showed that driving increased the blood pressure about 20 $\mathrm{mm}$ of mercury (40). In line with this research, $37.8 \%$ of Argentinean drivers had high blood pressure (13), and $53.3 \%$ and $49.9 \%$ of Korean drivers, respectively, had high blood pressure and metabolic syndrome (14). Research indicates that high blood pressure increases the risk of accidents about 3.82 times (41). Varmazyar et al. designed a research on health problems of bus drivers in Tehran, Iran, (25). Based on their results, 7.7, 5.5, 13.4, 13.7, and $18.9 \%$ of drivers had diabetes, heart diseases, high blood pressure, severe headaches, and other diseases such as hyperlipidemia and kidney stones, respectively. Moreover, 33\% of drivers older than 50 years in Denmark left their jobs because of gastrointestinal distress (1). A study that was conducted during the years 2005 to 2012 on 88,246 drivers revealed that $8.9 \%$ of drivers have gained weight during the study (11). Furthermore, hearing loss (15) 
and respiratory disorders (42) were common among the drivers. Based on the mentioned researches, it seems that drivers' quality of life (QOL) was lower than that of the public (21). However, as an intervention toward the improvement of lifestyles (43), avoiding longterm duration of driving (44), smoking (24), poor ergonomics $(11)$, and stress $(33,45)$ were recommended for professional drivers. The information in this study showed that more than $40 \%$ of drivers had experienced symptoms of anxiety and sleeplessness. These symptoms were reported in $23.6 \%$ and $14.5 \%$ of drivers of Peru (16) and the United States (1). Since driving requires continuous analysis of acquired data from the vehicle's condition and surroundings as well as a prediction of behaviors of other drivers, anxiety would be a destructive factor leading to accidents (7). Anxiety in drivers was a result of stress (6) and its root causes were very diverse such as unexpected occupational changes (45), U-turn when driving (46), violence $(7,9,21,45)$, environmental, technical, and interactive skills requirements (5), lack of legal and institutional support and overload of work schedules (9), high risk behavior of other drivers (35), intermediate variables such as personality, social support, and control (8), post-traumatic stress disorder (47), family problems (25), and family-work conflict (45). A study in England showed that 80 million working days were lost per year due to anxiety and depression (6). Bawa, in a study in 2013, showed that $67.1 \%$ of drivers were subject to stress and anxiety in heavy traffic (48).

Furthermore, the results of a meta-analysis on 183 studies revealed that anxiety and stress were in line with lack of job satisfaction and organizational commitment, leaving the job, and abnormal behavior (45). Moreover, anxiety is considered as a drive factor for highrisk behaviors (23). Anxiety is one of the most important factors that fatigue drivers quickly (5), and fatigue reduces their accuracy, and thus, causes accidents (49). Fatigue is usually accompanied with a combination of sleep disorders and lack of sufficient sleep. Fatigue, particularly in familiar roads, significantly reduces drivers' attention (6). Sleep that results from fatigue is a major cause of car accidents $(50,51)$. In a study, $43.7 \%$ of drivers reported sleepiness while driving (13). The results of a systematic review in 2014 showed that $19 \%$ of drivers suffered from sleep disorders (19). It was revealed that the impact of sleep disorders and sleeping on driving performance were equal to alcohol intoxication (52). Regular and continuous exercise can improve anxiety, fatigue, and sleep disturbances in terms of cognitive and psycho-physiological issues (6); hence, the application of this strategy for Iranian professional drivers is recommended. In addition, our results show that more than half of the studied drivers $(50.93 \%)$ suffered from social dysfunction. Pourabdian et al. (7) showed that violence was a common behavior among Iranian professional drivers. On the other hand, international researches have shown that transport workers, especially bus drivers, encountered higher risks of violence than other jobs (22). This mutual violence between drivers and passengers, greatly affects communication and social interaction. It seems that the awareness of the urban community regarding the important role of bus drivers, the development of plans to train drivers in order to promote interaction in management skills, and agreement between the drivers' demand to provide good services and time pressure (9) could improve the situation.

Depression was also measured in this study (13.08\%). Although there was no comprehensive information about depression among drivers, some studies have focused on this issue. Depression has been reported among $26.9 \%$ of truck drivers in the United States (12), 33\% of taxi drivers in Nigeria (1), and $15.6 \%$ of drivers in Peru (16). Depression affects the drivers' ability to focus (6) and was introduced as one of the psychological consequences of driving (8). Organization and the role of workers, lack of appropriate incentives, lack of opportunity to express complaints and suggestions, high 
responsibility and low decision-making capacity, lack of empathy between drivers and their coworkers and supervisors, and heavy traffic and violence were considered as risk factors for depression among drivers (9).

In general, it seems that a set of corrective measures such as providing a reasonable work schedule, reducing time pressure, training drivers about stress management, and implementing an appropriate health monitoring program (47) should be implemented for drivers. Moreover, provision of exercise motivation, establishment of a record-keeping and feedback system for complaints, enhancement of job and social security support, particularly in the case of medical insurance, improvement of the level of communication within the organization, and provision of opportunities for individual and organizational development, adequate wages, and balance between effort and reward (33) also seem necessary for drivers. The management of posttraumatic stress disorder (PTSD) (53), implementation of hearing protection programs (18), reduction of whole body vibration (38), the application of an appropriate rest-work system (44), and improvement of ultimate organizational safety climate should also be considered for professional drivers.

\section{Conclusion}

Based on our results and because of the rapid and significant impact of drivers' health on public health and safety, attention to this issue is crucial. The results of this study showed that although the increased risk of mental disorders was not considered in the average score of general health for the studied drivers, a high number of drivers were at risk of psychological disorders. Moreover, in future scientific literature, more attention to the impact of multiple occupational, environmental, and personal risk factors on the health of professional drivers, and drivers' human factors is recommended.

\section{Acknowledgments}

The authors would like to appreciate all honorable managers and the entire staff of the bus company for their gracious cooperation. The authors declare that there is no conflict of interests.

Conflict of interest: None declared.

\section{References}

1. Francis UC. The mental health status of taxi drivers in Lagos state, Nigeria. International Journal of Humanities Social Sciences and Education 2015; 2(2):142-51.

2. Gururaj G. Road traffic deaths, injuries and disabilities in India: current scenario. Natl Med J India 2008; 21(1):14-20.

3. Swiss. World Health Organization. Department of Violence and Injury Prevention. Road traffic injuries Report. World Health Organization; 2013. Available from: http://www.who.int/violence_injury_preventio n/road_traffic/en/

4. Thiese MS, Moffitt G, Hanowski RJ, Kales $\mathrm{SN}$, Porter RJ, Hegmann KT. Commercial driver medical examinations: Prevalence of obesity, comorbidities, and certification outcomes. J Occup Environ Med 2015; 57(6):659-65.

5. Sang Y, Li J. Research on Beijing bus driver psychology fatigue evaluation. Procedia Eng 2012; 43:443-8.

6. Taylor AH, Dorn L. Stress, fatigue, health and risk of road traffic accidents among professional drivers: the contribution of physical inactivity. Annu Rev Public Health 2006; 27:371-91.

7. Pourabdian S, Azmoon $\mathrm{H}$, Mirlohi $\mathrm{AH}$, Hassnzadeh A. Effect of state anxiety on driver behavior with regard to self-reported in Iranian drivers. Int J Environ Health Eng 2014; 3(1):812.

8. Tse JLM, Flin R, Mearns K. Bus driver wellbeing review: 50 years of research. Transp Res Part F Traffic Psychol Behav 2006; 9:89-114.

9. Hlotova Y, Cats O, Meijer S. Measuring bus driver's occupational stress under changing working conditions. Transp Res Rec 2014; 2415:13-20. doi:10.3141/2415-02.

10. Park J, Kim J, Lin DY, Waller ST. Job satisfaction and service quality of bus drivers in Korea. Asian Transport Studies 2011; 1(3):250-61.

11. Aini NA, Huda BZ. Prevalence of musculoskeletal symptoms and its associated risk factors among bus drivers in a university in Malaysia. International Journal of Public Health and Clinical Sciences 2015; 2(1):34-45.

12. Shattell M, Apostolopoulos Y, Collins C, Sönmez S, Fehrenbacher C. Trucking 
organization and mental health disorders of truck drivers. Issues Ment Health Nurs 2012; 33(7):436-44.

13. Pérez-Chada D, Videla AJ, O'Flaherty ME, Palermo P, Meoni J, Sarchi MI, et al. Sleep habits and accident risk among truck drivers: A cross-sectional study in Argentina. Sleep 2005; 28(9):1103-8.

14. Shin SY, Lee CG, Song HS, Kim SH, Lee HS, Jung MS, et al. Cardiovascular disease risk of bus drivers in a city of Korea. Ann Occup Environ Med 2013; 25(1):34. doi:10.1186/2052-4374-25-34.

15. Hirata RP, Sampaio LM, Leitão Filho FS, Braghiroli A, Balbi B, Romano S, et al. General characteristics and risk factors of cardiovascular disease among interstate bus drivers. ScientificWorldJournal 2012; 2012:216702. doi:10.1100/2012/216702.

16. Ruiz-Grosso P, Ramos M, Samalvides F, Vega-Dienstmaier J, Kruger H. Common mental disorders in public transportation drivers in Lima, Peru. PloS One 2014; 9(6): 101066 doi:10.1371/journal.pone.0101066.

17. Kunwar LB, Kunwar BB, Thapa P, Kaphle HP, Lekhak PC. Health problems in heavy vehicles drivers in far western Nepal. International Journal of Basic and Applied Medical Sciences 2014; 4(2):12-6.

18. Golmohammadi R, Damyar N, Mohammadfam I, Fardmal J. Evaluation of the relation between noise exposure and occupational stress with unsafe acts and accidents in city bus drivers. Iran Occupational Health Journal 2014; 11(1):70-8.

19. Abu Dabrh AM, Firwana B, Cowl CT, Steinkraus LW, Prokop LJ, Murad MH. Health assessment of commercial drivers: a metanarrative systematic review. BMJ Open 2014; 4:e003434. doi:10.1136/bmjopen-2013003434.

20. Xiong W, Xiong G, Yu W. Influence of sports prescription on taxi drivers' mental health in China. Journal of Beijing Sport University 2009; 10:66-8.

21. Wong CKH, Cheung Fung CS, Siu SC, Wong $\mathrm{KW}$, Lee KF, Lo YYC, et al. The impact of work nature, lifestyle, and obesity on healthrelated quality of life in Chinese professional drivers. J Occup Environ Med 2012; 54(8):989-94.

22. Lincoln R, Gregory A. Moving violations: a study of incivility and violence against urban bus drivers in Australia. Int $\mathbf{J}$ Educ Soc Sci 2015; 2(1):118-27.

23. Eysenck MW, Byrne A. Anxiety and susceptibility to distraction. Pers Individ Dif 1992; 13(7):793-8.

24. Jahangiri M, Karimi A, Slamizad S, Olyaei M, Moosavi S, Amiri F. 0BOccupational risk factors in Iranian professional drivers and their impacts on traffic accidents. International Journal of Occupational Hygiene 2013; 5(4):184-90.

25. Varmazyar S, Mortazavi SB, Arghami SH, Hajizadeh E. Effect of the mental and physical disorders status of Tehran's public transportation system bus drivers on the occurrence of crashes. Journal of Safety Promotion and Injury Prevention 2013; 1(3):168-75.

26. Emkani M, Khanjani N. Sleep quality and its related factors in intercity bus drivers. Iranian Journal of Military Medicine 2012; 14(2):13741.

27. Varmazyar S, Mortazavi SB, Arghami SH, Hajizadeh E. Factor analysis of driver behavior questionnaire (DBQ) in public transportation Bus Company: investigation of the relationship between DBQ factors and crashes. Scientific Journal of Review 2014; 3(4):155-65.

28. Ofili AN, Tobin EK, Ilombu MA, Igbinosun EO, Iniomor I. Job satisfaction and psychological health of long distance drivers in Benin city. International Journal of Community Research 2013; 2(4):64-71.

29. Noorbala AA, Bagheri yazdi SA, Mohammadi $K$. The validation of general health questionnaire-28 as a psychiatric screening tool. Hakim Research Journal 2009; 11(4):4753.

30. Nastiezaie N, Vaezi M, Molazahi A, Moghadam M. The relationship between job burnout and public health of telecommunication central office personnel in Zahedan. Toloo-E-Behdasht 2009; 7(3-4):4956.

31. Taghavi SMR. Assessing the validity and reliability of General Health Questionnaire (GHQ). Psychology 2002; 20:381-98.

32. Gardell B, Aronsson G, Barklof K. The working environment for local public transport personnel. $1^{\text {st }}$ ed. Stockholm, Sweden: The Swedish Work Environment Fund; 1982.

33. Chung YS, Wu HL. Stress, strain, and health outcomes of occupational drivers: An application of the effort reward imbalance model on Taiwanese public transport drivers. Transp Res Part F Traffic Psychol Behav 2013; 19:97-107.

34. Lakshman A, Manikath N, Rahim A, Anilakumari VP. Prevalence and risk factors of hypertension among male occupational bus drivers in north Kerala, south India: A CrossSectional Study. Int Sch Res Notices 2014; 2014:9. Article ID 318532, http://dx.doi.org $/ 10.1155 / 2014 / 318532$.

35. Useche S, Serge A, Alonso F. Risky behaviors and stress indicators between novice and experienced drivers. American Journal of Applied Psychology 2015; 3(1):11-14.

36. Nik Mahdi NNR, Bachok N, Mohamed N, Shafei MN. Risk factors for near miss incident among long distance bus drivers in Malaysia. Iran J Public Health 2014; 43(3):117-24.

37. Priyantha Wedagama DM. The influence of young and male motorists' accident: factors on motorcycle injuries in Bali. Introduction Assocation of Trafic and Safety Science Research 2009; 33(2):64-75.

38. Thamsuwan O, Blood RP, Ching RP, Boyle L, Johnson PW. Whole body vibration exposures in bus drivers: a comparison between a high- 
floor coach and a low-floor city bus. Int $\mathrm{J}$ Ind Ergon 2013; 43(1):9-17.

39. Borle A, Gunjal S, Jadhao A, Ughade S, Humne A. Musculoskeletal morbidities among bus drivers in city of central India. International Journal of Recent Trends in Science and Technology 2012; 3(1):29-32.

40. Narvadeh S, Moazenzadeh M, Mirzazadeh A. Driving environment in Iran increases blood pressure even in health taxi drivers. J R Soc Med 2008; 13(6):287-93.

41. Hours M, Fort E, Charnay P, Bernard M, Martin JL, Boisson D, et al. Diseases, consumption of medicines and responsibility for a road crash: A case-control study. Accid Anal Prev 2008; 40(5):1789-96.

42. Firdaus M, Jalaludin J. Exposure to indoor air pollutants (PM10, $\mathrm{CO} 2$ And $\mathrm{CO}$ ) and respiratory health effects among long distance express bus drivers. Health and the Environment Journal 2014; 5(5):66-85.

43. Puhkala J, Kukkonen-Harjula K, Mansikkamäki K, Aittasalo M, Hublin C, Kärmeniemi $\mathrm{P}$, et al. Lifestyle counseling to reduce body weight and cardiometabolic risk factors among truck and bus drivers - A randomized controlled trial. Scand J Work Environ Health 2015; 41(1):54-64.

44. Wang L, Pei Y. The impact of continuous driving time and rest time on commercial drivers' driving performance and recovery. J Safety Res 2014; 50:11-5.

45. Elci M, Sener I, Aksoy S, Alpkan L. The impact of ethical leadership and leadership effectiveness on employee's turnover intention:
The mediating role of work related stress. Procedia Soc Behav Sci 2012; 58:289-97.

46. Benedi PM. The "cognitive turn": A short guide for nervous drivers. Status Quaestionis 2014; 7:127-55.

47. Chung YS, Wong JT. Developing effective professional bus driver health programs: an investigation of self-rated health. Accident Analysis and Prevention 2011; 43(6):2093-103.

48. Bawa MS, Srivastav M. Study the epidemiological profile of taxi drivers in the background of occupational environment, stress and personality characteristics. Indian J Occup Environ Med 2013; 17(3):108-13.

49. Abang Abdullah DNM, Von HL. Factors of fatigue and bus accident. Paper presented at: The $2^{\text {nd }}$ International Conference on Innovation, Management and Service; 2011 September 16-18; Singapore, Indonesia.

50. Herman J, Ameratunga SN, Wainiqolo I, Kafoa B, Robinson E, McCaig E, et al. Prevalence of sleepiness while driving four-wheel motor vehicles in Fiji: a population-based survey. Inj Prev 2013; 19(4):271-5.

51. Quan SF, Barger LK. Brief review: sleep health and safety for transportation workers. Southwest J Pulm Crit Care 2015; 10(3):130-9.

52. Dawson D, Reid K. Fatigue, alcohol and performance impairment. Nature 1997; 338(6639):235.

53. Kim HR, Yim HW, Jo SJ, Choi B, Jeong SH, Lee KS, et al. Major depressive disorder, panic disorder, and post-traumatic stress disorder in Korean subway drivers. Int Arch Occup Environ Health 2013; 86(4):471-7. 